\title{
OPTIMALISASI PENDAPATAN PETANI CABAI MERAH DENGAN DIVERSIFIKASI USAHATANI
}

\section{OPTIMIZATION OF INCOME OF RED CHILI FARMERS WITH FARMING DIVERSIFICATION}

\author{
Benidzar M Andrie, Ane Novianty \\ Fakultas Pertanian Universitas Galuh \\ Jl. R.E Martadinata No 150. Ciamis 46274 \\ *beni.andrie1992@gmail.com \\ (Diterima 14-11-2020; Disetujui 29-12-2020)
}

\begin{abstract}
ABSTRAK
Tumpang sari merupakan salah satu cara untuk meningkatkan efisensi penggunaan lahan melalui usaha penanaman beberapa jenis tanaman pada lahan dan waktu yang sama. Penanaman yang diatur sedemikian rupa dalam barisan-barisan tanaman akan membantu usaha pencapaian potensi produksi dari kedua jenis tanaman yang ditumpangsarikan. Penelitian ini bertujuan untuk mengetahui besarnya penerimaan, pendapatan, kelayakan dan titik impas (Break even Point, BEP) usahatani cabai merah dengan diversifikasi usahatani di Kecamatan Bojonggambir. Metode penelitian yang digunakan adalah survei pada petani yang melakukan usahatani dengan diversifikasi tanaman cabai merah secara kontinyu. Hasil penelitian dengan luas lahan 0,34 menunjukkan bahwa penerimaan petani sebesar Rp 9.590.000,00, total biaya Rp 3.699.000 sehingga pendapatan sebesar Rp 5.891.000 selama enam bulan, untuk kelayakan yang dilihat dari nilai R-C ratio yaitu sebesar 2,6 dan untuk BEP unit sebesar 51,90 kg, BEP penerimaan Rp 578.246 dan BEP harga jual Rp 3.111/kg dengan jumlah produksi $858,25 \mathrm{~kg}$ dari total produksi artinya bahwa secara finansial usaha ini layak.
\end{abstract}

Kata kunci: Optimalisasi, Usahatani Cabai Merah, diversifikasi

\section{ABSTRACT}

Intercropping is one way to increase land use efficiency by planting several types of plants on the same land at the same time. Planting that is arranged in such a way in plant rows will help efforts to achieve the production potential of the two types of intercropped plants. This study aims to determine the amount of revenue, income, and eligibility in Bojonggambir District. The research method used was a survey on farmers who carried out farming with continuous red chili crop diversification. The results of this study with a land area of 0.34 indicate that the income of farmers is $R p .9,590,000.00$, with a total cost of $R p .3,699,000$ so that you get an income of $R p$. 5,891,000 for six months, for eligibility as seen from the RC ratio value of 2.6 and for the Break Even Point (BEP) Unit of $51.90 \mathrm{~kg}$, BEP (Rp) Rp. 578,246 and BEP (Selling Price) Rp. 3,111/ kg with a total production of $858.25 \mathrm{~kg}$ of the total production means that this business is financially feasible

Keywords: Optimization, red chili farming, diversification

\section{PENDAHULUAN}

Indonesia dikenal sebagai negara

agraris yang berarti negara yang

mengandalkan sektor pertanian, baik sebagai sumber mata pencaharian maupun sebagai penopang pembangunan.

Kuncoro (2010). Sektor pertanian hortikultura merupakan sub-sektor 
pertanian yang memiliki peranan yang penting dalam perekonomian Indonesia. Komoditas hortikultura, khususnya sayuran dan buah-buahan mempunyai beberapa peranan strategis, yaitu: (1) sumber bahan makanan bergizi bagi masyarakat yang kaya akan vitamin dan mineral; (2) sumber pendapatan dan kesempatan kerja, serta kesempatan berusaha; (3) bahan baku agroindustri; (4) sebagai komoditas potensial ekspor yang merupakan sumber devisa negara; dan (5) pasar bagi sektor non pertanian, khususnya industri hulu. Subsektor hortikultura memberikan peningkatan kontribusi yang cukup siginifikan terhadap PDB yaitu dalam kurun waktu 2003-2008, meningkat 32,9\% dari sebesar 53,89 triliun rupiah menjadi 80,29 triliun rupiah. Selain itu, juga dari sektor pertanian memberikan kontribusi GDP sebesar 11,36\%, hortikultura menyumbang $16 \%$ dengan proporsi kenaikan sebesar $68,6 \%$ dalam kurun waktu 2012 - 2013. (BPS, 2014)

Indonesia dengan potensi sumber daya lahan dan agroklimat yang beragam berpeluang untuk mengembangkan berbagai tanaman hortikultura tropis, yang mencakup 323 jenis komoditas (Dirjen Hortikultura, 2012). Salah satu komoditas hortikultura adalah cabai merah. Cabai merah mempunyai karakteristik cepat busuk, rusak, dan susut besar merupakan masalah yang dapat menimbulkan risiko produksi dan harga. Harga yang fluktuatif membuat usahatani cabai merah menjadi berisiko tinggi. Selain itu, faktor cuaca dan gangguan organisme menjadi faktor yang perlu diperhatikan pada usahatani cabai merah. Jika ditinjau dari segi permintaan, tanaman cabai merah mempunyai arti penting bagi keperluan sehari-hari sehingga cabai merah mempunyai prospek untuk dibudidayakan.

Usahatani sangat penting di bidang pertanian agar petani bisa bertani secara berkelanjutan untuk mendukung ketahanan pangan nasional seperti yang dicanangkan oleh pemerintah dan penanggulangan kemiskinan karena bertani merupakan mata pencaharian petani yang berdampak pada perekonomiannya. Kadarsan dalam Shinta (2011) menjelaskan bahwa usahatani adalah suatu tempat dimana seseorang atau sekelompok orang berusaha mengelola unsur-unsur produksi seperti alam, tenaga kerja, modal dan keterampilan dengan tujuan berproduksi untuk menghasilkan sesuatu dilapangan pertanian. 
Tumpang sari merupakan salah satu cara untuk meningkatkan efisensi penggunaan lahan melalui usaha penanaman beberapa jenis tanaman pada lahan dan waktu yang sama. Penanaman yang diatur sedemikian rupa dalam barisan-barisan tanaman akan membantu usaha pencapaian potensi produksi dari kedua jenis tanaman yang ditumpangsarikan. Penundaan waktu tanam dari satu jenis tanaman yang ditumpangsarikan juga dimaksudkan agar saat pertumbuhan maksimum terjadi pada waktu yang tidak bersamaan. Hal ini akan membantu usaha pencapaian potensi produksi dari kedua jenis tanaman yang ditumpangsarikan (Arma, Fermin \& Sabaruddin 2013)

Penelitian ini bertujuan untuk mengetahui besarnya biaya, penerimaan, pendapatan, kelayakan dalam diversifikasi usahatani komoditas cabai merah, serta Break Even Point (BEP) dalam unit, rupiah dan harga jual untuk diversifikasi usahatani komoditas cabai merah.

\section{METODE PENELITIAN}

Metode yang digunakan dalam penelitian ini adalah metode survey. Menurut Sugiyono (2017) penelitian survey adalah penelitian yang dilakukan pada populasi besar maupun kecil, tetapi data yang dipelajari adalah data dari sampel yang diambil dari populasi tersebut, sehingga ditemukan kejadiankejadian relatif, distribusi, dan hubunganhubungan antar variabel sosiologis maupun psikologis. Dalam penelitian ini diambil sampel petani cabai merah yang melakukan diversifikasi usahatani ada 20 petani yang melakukan usahataninya secara kontinyu.

Pengambillan sampel diambil secara sensus yang berjumlah 20 orang petani yang mengusahakan diversifikasi usahatani cabai merah dengan bawang merah di Desa Bojonggambir Kecamatan Bojonggambir Kabupaten Tasikmalaya Teknik sensus digunakan berdasarkan hasil survei di lapangan bahwa relatif sedikitnya jumlah populasi petani yang mengusahakan usahatani diversifikasi cabai merah dengan bawang merah di daerah dataran tinggi secara kontinyu dan sudah lama mengusahakan usahataninya.

Operasional variabel berfungsi mengarahkan variabel-variabel yang digunakan didalam penelitian ini ke indikator-indikatornya secara kongkret, yaitu berguna dalam pembahasan hasil dari penelitian. Hal tersebut dilakukan untuk menghindari salah satu persepsi dan pemahaman terhadap variabel- 
variabel yang digunakan dalam suatu penelitian. Variabel-variabel yang diamati dalam penelitian ini meliputi:

1) Responden adalah petani yang usahataninya komoditas cabai yang di tumpang sari dengan bawang merah.

2) Biaya Tetap (Fixed Cost) yaitu biaya produksi yang besar kecilnya tidak dipengaruhi oleh besar kecilnya volume produksi dan sifatnya tidak habis dalam satu periode produksi. Biaya tetap tersebut terdiri dari :

a. Biaya lahan yang digunakan adalah biaya sewa yang dihitung dalam rupiah pertahun ( $\mathrm{Rp} / \mathrm{thn})$.

b. Penyusutan alat yang digunakan dalam proses produksi dinilai dalam satuan rupiah per tahun ( $\mathrm{Rp} / \mathrm{thn})$, selanjutnya dikonversikan ke dalam periode produksi. Penyusutan bangunan, mesin dan alat-alat ini dihitung dengan formulasi sebagai berikut (Ken Suratiah, 2008).

Penyusutan Alat $=\frac{\text { Nilai Beli- } \text { Nilai Sisa }}{\text { Umur Ekonomi }}$
Perhitungan penyusutan alat
dilakukan bersama-sama dengan
alasan alat-alat digunakan bersama
dan sulit untuk mensplit

penggunaannya untuk masingmasing tanaman.

c. Bunga Modal tetap dihitung dalam satuan rupiah per tahun (Rp/thn) berdasarkan bunga Bank yang berlaku pada saat penelitian.

Bunga Modal $=($ sewa lahan + penyusutan alat ) $\mathrm{x}$ suku bunga pinjaman

3) Biaya Variabel (Variable Cost) yaitu biaya-biaya yang besar kecilnya tergantung pada besar kecilnya volume produksi. Biaya variabel yang dianalisa dalam penelitian ini terdiri dari biaya:

a. Benih adalah jumlah biji cabai merah dan bawang merah jumlah umbi yang dinyatakan dalam satuan rupiah (Rp).

b. Polybag yang digunakan untuk persemaian adalah terbuat dari bahan plastik yang dinyatakan dalam satuan $\mathrm{kg}$ dan dinilai dalam satuan rupiah/(Rp)

c. Pupuk anorganik yang digunakan dalam penelitian TSP, KCL, Phonska dan ZA dihitung dalam satuan kilogram dan dinilai dalam satuan rupiah $(\mathrm{Rp})$

d. Pupuk organik yang digunakan adalah kotoran hewan yang 
dinyatakan dalam satuan kilogram dan dinilai dalam satuan rupiah $(\mathrm{Rp})$

e. Kapur yang digunakan adalah kapur dolomit yang dinyatakan dalam satuan kilogram dan dinilai dalam satuan rupiah $(\mathrm{Rp})$

f. Plastik mulsa yang dinyatakan dalam satuan rol (meter) dan dinilai dalam satuan Rupiah (Rp)

g. Ajir yang digunakan adalah dari bahan bambu yang dinyatakan dalam satuan batang dan dinilai dalam satuan rupiah $(\mathrm{Rp})$

h. Tali rapia yang dinyatakan dalam satuan rol dan dinilai dalam satuan rupiah ( $R p)$

i. Pestisida yang digunakan adalah pestisida yang sesuai dengan kebutuhan tanaman, dihitung dalam satuan liter atau larutan tank sprayer dan dinilai dalam satuan rupiah $(\mathrm{Rp})$

j. Tenaga kerja yang terdiri dari tenaga kerja pria dan tenaga kerja wanita dihitung dalam satuan Hari Orang Kerja (HOK) dan dinilai dalam satuan hitung rupiah ( $\mathrm{Rp} /$ hari/orang)

4) Penerimaan hasil penjualan adalah jumlah produksi fisik produk dikalikan harga persatuan produk tersebut:

a. Hasil produksi dihitung dalam satuan kilogram (Kg) b. Harga jual dihitung dalam satuan rupiah per kilogram $(\mathrm{Rp} / \mathrm{kg})$

5) Pendapatan atau laba adalah hasil pengurangan antara penerimaan dengan biaya total dan dinilai atau dinyatakan dalam satuan rupiah

6) $\mathrm{R}-\mathrm{C}$ ratio adalah imbangan antara penerimaan dengan biaya produksi total

7) Analisis Break Even Point (BEP) dalam penelitian ini ada tiga jenis yaitu:

a. Break Even Point dalam unit digunakan, dinyatakan dalam satuan kilogram $(\mathrm{Kg})$

b. Break Even Point dalam rupiah, dinyatakan dalam satuan rupiah ( $\mathrm{Rp}$ )

c. Break Even Point dalam harga jual, dinyatakan dalam satuan rupiah per kilogram $(\mathrm{Rp} / \mathrm{Kg})$

8) Penelitian ini dilakukan selama satu periode produksi.

Analisis Kelayakan (R/C Ratio)

Pemaparan data yang dikumpulkan ditabulasi dan dianalisis secara deskriptif dengan menggunakan analisis usahatani yang meliputi analisis biaya, penerimaan, pendapatan, dan R/C Ratio. Menurut Suratiyah (2006), analisis data yang dimaksud dijabarkan sebagai berikut: 
Untuk mengetahui besarnya biaya dihitung dengan rumus sebagai berikut:

$\mathrm{TC}=\mathrm{TFC}+\mathrm{TVC}$

$\mathrm{TVC}=\sum \mathrm{TVCi}$

Keterangan:

$\mathrm{TC} \quad=$ Total Cost (biaya total)

TFC = Total Fixed Cost (biaya tetap total)

TVC = Total Variable Cost (biaya variabel total)

$\sum \mathrm{TVCi}=$ jumlah biaya total dari ke 2 komoditas

$\mathrm{i}=$ jenis komoditas yang diusahakan

Untuk mengetahui besarnya penerimaan dihitung dengan rumus sebagai berikut:

$\mathrm{TR}=\mathrm{Y}$. Py

Keterangan:

$\mathrm{TR}=$ Total Revenue (penerimaan total)

$\mathrm{Y} \quad=$ Jumlah Produksi (kilogram)

Py = Harga Jual Produk $(\mathrm{Rp} / \mathrm{kg})$

$\mathrm{TR}=\sum \mathrm{Yi}$. Pyi

$\mathrm{TR}=\mathrm{Y} 1 \mathrm{P} 1+\mathrm{Y} 2 \mathrm{P} 2$

Pendapatan petani dihitung dengan rumus sebagai berikut:

$\mathrm{I}=\mathrm{TR}-\mathrm{TC}$

Keterangan:

I $\quad=$ Income (pendapatan).

$\mathrm{TR}=$ Total Revenue (penerimaan total).

TC = Total Cost (biaya total).
Untuk mengetahui besarnya $\mathrm{R} / \mathrm{C}$ dihitung dengan menggunakan rumus sebagai berikut:

$\mathrm{R} / \mathrm{C}=\mathrm{TR} / \mathrm{TC}$

Dengan ketentuan:

- Apabila R/C > 1, maka usahatani tersebut menguntungkan.

- Apabila R/C = 1, maka usahatani tersebut tidak untung tidak rugi

- Apabila R/C < 1, maka usahatani tersebut merugi.

\section{Analisis Break Even Point (BEP)}

Untuk mengetahui kondisi Break Even Point (BEP) pada usahatani diversifikasi cabai merah dikenal beberapa konsep BEP, diantaranya BEP Penerimaan, BEP Produksi, dan BEP Harga.

Untuk menganalisis BEP dalam unit digunakan rumus: (Sabar dan Briman, 2010)

$B E P($ unit $)=$

Biaya Tetap Hasil Penjualan/unit Biaya Variabel/unit

Untuk menganalisis BEP dalam rupiah digunakan rumus (Sabar dan Briman, 2010):

$B E P($ Rupiah $)=$

$$
\frac{\text { Biaya Tetap }}{1-\frac{\text { Biaya Variabel }}{\text { Hasil Penjualan }}}
$$


Untuk menganalisis BEP dalam harga jual digunakan rumus (Sabar dan Briman, 2010):

$$
B E P(\text { harga jual })=\frac{\mathrm{a}+\mathrm{b} \mathrm{x}}{\mathrm{x}}
$$

Dimana :

$$
\begin{aligned}
& \mathrm{x}=\text { Kuantitas produksi/penjualan } \\
& \mathrm{a}=\text { Total Biaya Tetap } \\
& \mathrm{b}=\text { Biaya Variabel per Unit }
\end{aligned}
$$

Kriteria yang akan dicapai:

BEP $<$ produksi di tingkat produsen, maka usaha tersebut menguntungkan atau efisien untuk diusahakan

$\mathrm{BEP}=$ produksi di tingkat produsen, maka usaha tersebut dikatakan impas

BEP > produksi di tingkat produsen, maka usaha tersebut dikatakan rugi atau tidak efisien untuk diusahakan.

\section{HASIL DAN PEMBAHASAN}

\section{Identitas Responden}

Petani Responden pada penelitian ini adalah petani yang melakukan diversifikasi pola tanam Cabai Merah dengan Bawang Meraht secara kontinyu. Responden petani diambil dari dua desa di Kecamatan Bojonggambir yaitu Desa Bojonggambir dan Desa Kertanegla. Indikator yang digunakan dalam mengidentifikasi petani sebagai responden adalah umur, pendidikan, dan tanggungan keluarga.
Umur berpengaruh langsung terhadap kemampuan fisik dan respon petani terhadap inovasi baru. Petani usia muda relatif lebih baik kekuatannya dibandingkan dengan petani yang berusia lanjut, begitu juga dalam menerima inovasi baru biasanya petani berusia muda lebih optimis dan responsif. Jumlah petani yang diambil sebagai responden dalam penelitian ini sebanyak 20 orang. Tingkat produktifitas dalam usaha ternak sapi perah dapat dipengaruhi oleh tingkat umur petani tersebut. Menurut Said Rusli (1995), penduduk usia produktif adalah penduduk yang berumur antara 15 sampai 64 tahun. Komposisi umur petani responden dapat dilihat pada Gambar 1.

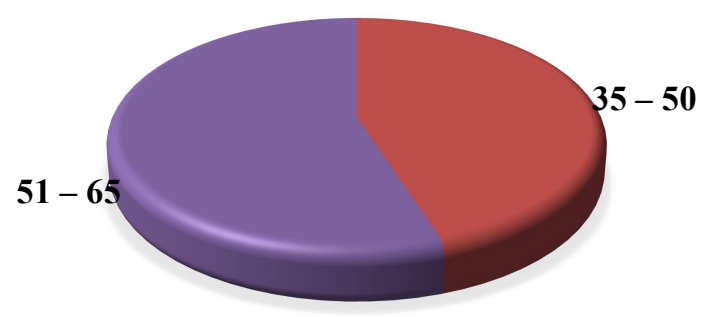

\section{Gambar 1. Umur Petani}

Berdasarkan Gambar 1, terlihat bahwa umur responden berkisar dari 35 sampai 61 tahun dan kebanyakan umur responden berada di kisaran 40 sampai 59 tahun. Keadaan ini menunjukkan bahwa 
semua petani cabai merah yang melakukan diversifikasi pola tanam di Kecamatan Bojonggambir berada dalam usia produktif, sehingga dapat melaksanakan usahatani diversifikasi pola tanam dengan sebaik-baiknya. Kemampuan petani dalam mengelola usahatani seiring semakin produktif umurnya maka mempunyai kecenderungan bertambah pula kemampuan dalam mengelola usahataninya ke tingkat yang lebih berhasil dan berkembang ke arah yang lebih maju.

Pendidikan merupakan suatu proses yang dapat meningkatkan ilmu pengetahuan dan keterampilan seseorang dalam menyelesaikan berbagai permasalahan yang dihadapinya, oleh karena itu tingkat pendidikan formal petani responden tentunya mempengaruhi keadaan perilaku yang terdiri dari pengetahuan, sikap serta keterampilan petani dalam mengelola usahataninya termasuk pada usahatani diversifikasi pola tanam ataupun usaha di luar pertanian. Perilaku berusaha diversifikasi pola tanam, petani responden banyak yang berasal dari pengalaman petani itu sendiri atau petani di sekitarnya atau petani di tempat lain, namun tingkat pendidikan untuk melakukan perubahan perilaku responden diantaranya dilakukan juga melalui pendidikan non formal. Untuk lebih jelasnya tingkat pendidikan responden dapat dilihat pada Gambar 2.

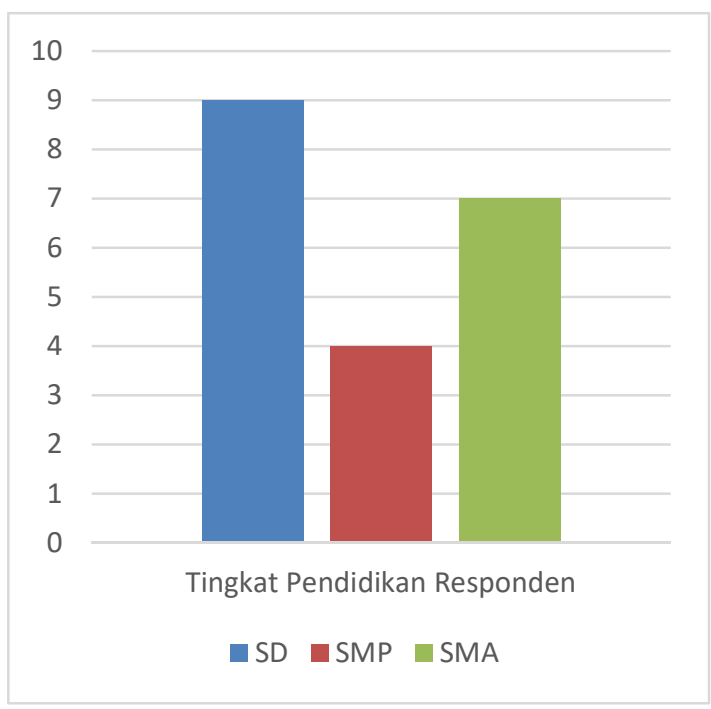

Gambar 2. Pendidikan Petani

Gambar 2 memperlihatkan bahwa tingkat pendidikan responden sebagian besar 9 responden hanya sampai lulusan $\mathrm{SD}$, sedangkan sisanya lulusan SLTP, 4 responden dan lulusan SMA, 7 responden. Tingkat pendidikan yang telah ditempuh tentunya akan mempengaruhi sikap dan cara petani dalam merespon teknologi dan inovasi baik dalam usaha ternak ataupun teknologi dan inovasi yang lainnya. Tingkat pendidikan juga sangat berpengaruh terhadap kemampuan petani untuk memperoleh informasi pasar yang merupakan hal yang sangat penting dalam menunjang aktivitas pemasaran petani. 
Semakin banyaknya tanggungan keluarga berarti semakin banyak atau semakin besar yang harus ditanggung keluarga. Besarnya anggota keluarga akan mempengaruhi dinamika dan kinerja petani responden dalam melakukan aktivitas kehidupannya sehingga harus lebih giat lagi dalam melakukan kegiatan usahanya sampai memperoleh keuntungan yang dapat mencukupi kebutuhan tanggungan keluarga petani responden.

Banyaknya anggota keluarga yang berusia produktif mampu menjadi aset keluarga apabila mempunyai pekerjaan yang menjadi sumber pendapatan sehingga mampu memberi kontribusi terhadap keluarga. Jumlah tanggungan keluarga meliputi kepala keluarga, istri, anak dan anggota keluarga lainnya yang menjadi tanggungan.

Petani responden umumnya sudah berkeluarga dengan jumlah tanggungan keluarga rata-rata 3 orang yang terdiri dari istri, anak yang belum sekolah dan anak yang sudah sekolah. Jumlah tangungan kelurga petani responden yang paling banyak adalah 6 orang dan paling sedikit adalah 3 orang. Untuk lebih jelasnya mengenai jumlah tanggungan keluarga petani responden dapat dilihat pada grafik berikut ini.

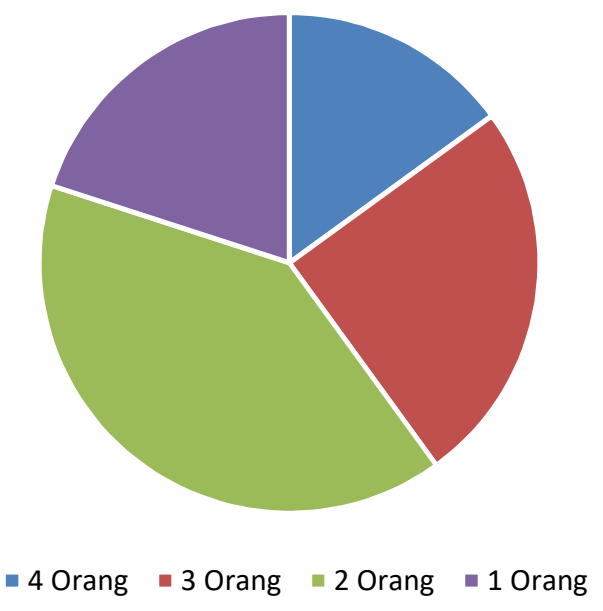

Gambar 3. Tanggungan Keluarga

\section{Analisis Biaya Diversifikasi Usahatani}

\section{Cabai Merah}

Biaya usahatani diversifikasi dalam penelitian ini dihitung per satu periode produksi tanaman yang memiliki umur produksi paling panjang, dimulai dari pengolahan sampai dengan proses pemanenan. Biaya yang akan dihitung diantaranya biaya tetap, biaya variabel dari cabai merah dan bawang merah, penerimaan dan pendapatan, $\mathrm{R}-\mathrm{C}$ ratio yang merupakan alat pembanding antara hasil penerimaan dengan biaya total produksi.

Biaya Tetap pada Diversifikasi Usahatani Cabai Merah

Biaya tetap adalah biaya yang digunakan untuk membeli atau menyediakan bahan baku yang habis dalam satu musim tanam dan besar 
kecilnya tidak dipengaruhi oleh volume produksi. Biaya tetap yang diteliti dan dilaksanakan oleh petani responden terdiri dari:

Biaya penyusutan alat dihitung berdasarkan jumlah kepemilikan alat pertanian yang digunakan dalam usahatani diversifikasi. Petani responden memiliki cangkul, spayer, parang, ember, golok, linggis, dan drum. Penyusutan alat dihitung dengan cara menaksir jangka umur ekonomis alat tersebut untuk mencangkul, biasanya umur ekonomis mencapai 2-3 tahun, spayer 2-3 tahun, parang 2-3 tahun, linggis 4-5 tahun, ember 1 tahun, drum 3-4 tahun, golok 23 tahun. Setelah dihitung, rata-rata biaya penyusutan alat untuk luas tanam ratarata 0,34 hektar mencapai $\mathrm{Rp} 290.500$ per periode (satu kali musim tanam).

Biaya tetap lainya adalah biaya bunga modal. Perhitungan biaya bunga modal dalam penelitian ini adalah menghitung jumlah biaya tetap dan dikalikan dengan bunga BANK yang berlaku di BRI Unit Bojonggambir sebesar 14 persen dalam setahun.

Tabel 1. Rata-rata Rincian Jumlah Biaya Tetap pada Diversifikasi usahatani sayuran per 0,34 ha per periode produksi

\begin{tabular}{clc}
\hline No & Uraian & Besarnya \\
\hline 1 & Penyusutan Alat & $290.000,00$ \\
2 & Bunga Modal & $155.250,00$ \\
\hline & Jumlah & $\mathbf{4 4 5 . 2 5 0 , 0 0}$ \\
\hline
\end{tabular}

Sumber: Analisis Data Primer (2020)
Tabel 1 menunjukan bahwa besarnya biaya tetap pada usaha diversifikasi adalah biaya penyusutan alat yaitu sebesar Rp 290.500,00 dan Rp. 155.250,00 untuk bunga modal dikalikan 6 bulan periode tanam. Biaya usahatani diversifikasi dalam penelitian ini dihitung per satu periode produksi tanaman yang memiliki umur produksi paling panjang, dimulai dari pengolahan sampai dengan proses pemanenan. Biaya yang akan dihitung diantaranya biaya tetap, biaya variabel dari cabai merah dan bawang merah, penerimaan dan pendapatan, $\mathrm{R}-\mathrm{C}$ ratio yang merupakan alat pembanding antara hasil penerimaan dengan biaya total produksi.

Tabel 2. Biaya Total pada Diversifikasi Cabai Merah per 0,34 ha per periode produksi

\begin{tabular}{ccc}
\hline No & \multicolumn{1}{c}{ Uraian } & Besarnya (Rp) \\
\hline 1 & Biaya Tetap & 445.250 \\
2 & Biaya Variabel & 3.253 .750 \\
\hline & Jumlah & $\mathbf{3 . 6 9 9 . 0 0 0}$
\end{tabular}

Sumber: Analisis Data Primer (2020)

Rata-rata biaya total yang dikeluarkan untuk kegiatan diversifikasi cabai merah yang ditanam pada luas lahan 0,34 hektar per musim tanam (6 bulan) sebesar $\mathrm{Rp} 3.699 .000$ dan dari biaya total tersebut paling besar dikeluarkan adalah biaya variabel sebesar Rp 3.253.750.

Penerimaan merupakan hasil kali antara jumlah produksi dengan harga 
jual. Penerimaan dalam kegiatan diversifikasi cabai merah yang dilakukan petani responden di Kecamatan Bojonggambir untuk cabai merah $\mathrm{Rp}$ 6.165.000 dan Bawang merah Rp 3.425 .000 per 0,34 hektar. Penerimaan yang diperoleh petani cukup besar, hal ini disebabkan karena produksi bawang merah yang merupakan tanaman selang pada cabai merah selain untuk mengurangi resiko dalam usahatani fungsinya juga untuk mengurangi gangguan hama dan penyakit cabai merah. rata Total Penerimaan pada Diversifikasi Cabai Merah Rp 9.590.0000.

Pendapatan diversifikasi cabai merah mendapat keuntungan sebesar Rp 5.891 .000 dan untuk $\mathrm{R}-\mathrm{C}$ ratio merupakan perbandingan antara hasil penerimaan dengan biaya total produksi. Berdasarkan Tabel 5, penerimaan pada diversifikasi cabai merah yang ditanam pada luas 0,34 hektar sebesar Rp 9.590.000. Penerimaan berasal dari cabai merah dan bawang merah dalam 1 produksi (6 bulan) dan dibagi dengan biaya total yang dikeluarkan untuk diversifikasi cabai merah yaitu sebesar Rp 3.699.000 per 0,34 hektar per satu musim periode (6 bulan). Maka akan diperoleh nilai R-C ratio sebesar 2,6
Artinya bahwa setiap 1 (satu) rupiah yang di keluarkan akan menghasilkan keuntungan sebesar 1,6 rupiah. Dan dapat diambil kesimpulan bahwa diversifikasi usahatani sayuran ini layak untuk diusahakan.

\section{Break Even Point Diversifikasi}

\section{Usahatani Cabai Merah}

Tingkat BEP dapat dilakukan terhadap jumlah barang yang diproduksi atau dijual maupun terhadap besarnya jumlah penghasilan dalam jumlah uang (Sabar Sutia dan Brima Tambunan, 2010). Berdasarkan data biaya tetap, biaya variabel, dan penerimaan dari responden maka nilai BEP dapat kita hitung sebagai berikut:

BEP (Unit)

$$
\begin{aligned}
& =\frac{\text { Biaya Tetap }}{\text { (Hasil Penjualan:Unit)-(Biaya Variabel:Unit })} \\
& =\quad \frac{445.250}{(9.560 .000: 858.25)-(2.226 .250: 858,25)} \\
& =\quad 51,90 \mathrm{~kg} \\
& \text { Dari perhitungan dapat dilihat }
\end{aligned}
$$
petani mengalami keadaan tidak untung dan tidak rugi atau BEP dalam unit sebesar 51, $90 \mathrm{~kg}$ untuk cabai merah dan bawang merah untuk masa panen dalam 6 bulan. Cabai merah panen dalam 6 bulan akan mendapatkan produksi $685 \mathrm{~kg}$ dan bawang merah $171,25 \mathrm{~kg}$ dalam lahan rata-rata 0,34 ha. Proporsi cabai merah dan bawang merah $80 \%$ dan $20 \%$ dari 
total keseluruhan BEP, jadi BEP per komoditas untuk cabai merah yaitu 41,52 $\mathrm{kg}$ sedangkan untuk bawang merah BEP nya yaitu $10,38 \mathrm{~kg}$.

Penerimaan per 0,34 ha per 6 bulan sebesar Rp9.950.000, ini menandakan bahwa diversifikasi usahatani cabai merah memberikan keuntungan karena penerimaan riil jauh di atas BEP (Rupiah). Dan jika melihat tingkat kelayakan maka usahatani ini layak dikembangkan mengingat penerimaan riil $>$ BEP (Rupiah), yaitu Rp9.950.000 > Rp 578.246, seperti yang dikatakan oleh Ken Suratiyah (2009), bahwa evaluasi kelayakan usaha berdasarkan beberapa kategori, dikatakan layak jika memenuhi persyaratan antara lain Penerimaan Riil $($ Rupiah) $>$ BEP Penerimaan (Rupiah).

BEP (Rupiah)

$$
\begin{aligned}
& =\frac{\text { Biaya Tetap }}{1-\frac{\text { Biaya Variabel }}{\text { Hasil Penjualan }}} \\
& =\frac{445.250}{1-\frac{2.226 .250}{9.950 .000}} \\
& =\text { Rp. } 578.246 .
\end{aligned}
$$

\section{BEP (Harga Jual)}

$=\frac{\text { Biaya Tetap }+(\text { Biaya Variabel } / \text { Unit X Jumlah Produksi }}{\text { Jumlah Produksi }}$

$=\frac{445.250+(2.593,18 \times 858,25)}{858,25}$

$=\mathrm{Rp} .3 .111 / \mathrm{kg}$

Hasil perhitungan BEP Harga Jual (dengan nilai BEP Produksi) memperlihatkan bahwa petani cabai merah di Kecamatan Bojonggambir mengalami titik impas atau break even atau tidak untung dan tidak rugi jika responden menjual hasil produksinya dengan harga Rp3.111/kg dengan jumlah produksi sebanyak 858,25 $\mathrm{kg}$ (BEP Produksi). Petani akan mengalami keuntungan apabila menjual di atas $\mathrm{Rp}$ $3.111 / \mathrm{kg}$ dan akan mengalami kerugian apabila menjual di bawah dari $\mathrm{Rp}$ $3.111 / \mathrm{kg}$. Dengan membandingkan harga jual berdasarkan produksi riil dan BEP produksi (unit) maka petani cabai merah memiliki dasar harga jual sehingga dapat kuat dalam hal tawar menawar. Jika produksinya 858,25 karung maka harga jual harus di atas $\operatorname{Rp} 3.111 / \mathrm{kg}$ supaya petani untung.

\section{KESIMPULAN DAN SARAN}

\section{Kesimpulan}

1. Biaya total rata-rata diversifikasi usahatani komoditas cabai merah per usahatani (0,34 ha) selama satu musim tanam ( 6 bulan) di Kecamatan Bojonggambir adalah senilai $\mathrm{Rp}$ 3.699.000, Penerimaan Rp 9.590.000, Pendapatan senilai Rp 5.891.000 dan Nilai kelayakan R/C Ratio diversifikasi usahatani komoditas cabai merah selama satu 
musim tanam (6 bulan) adalah senilai 2,6 .

2. BEP dalam unit diversifikasi usahatani komoditas cabai merah adalah 51,90 kg, BEP dalam rupiah sebesar Rp 578.246 dan BEP dalam harga jual pada diversifikasi usahatani komoditas cabai merah, Kecamatan Bojonggambir, Kabupaten Tasikmalaya adalah sebesar $\mathrm{Rp}$ $3.111 / \mathrm{kg}$ dengan jumlah produksi BEP (unit) yaitu $858,25 \mathrm{~kg}$ dari total produksi.

\section{Saran}

Petani diharapkan mengembangkan usahatani diversifikasi cabai merah dan bawang merah, dikarenakan usahatani cabai merah dan bawang merah menguntungkan sehingga dapat memperbaiki perekonomian petani di daerah tersebut dan mengurangi resiko ketergantungan dalam satu komoditas dalam usahatani.

\section{UCAPAN TERIMA KASIH}

Penulis menyampaikan ucapan terima kasih kepada yang terhormat Direktorat Penelitian dan Pengabdian Kepada Masyarakat (DP2M), Direktorat Jenderal Pendidikan Tinggi, Kementerian Pendidikan dan Kebudayaan Republik
Indonesia yang telah membiayai penelitian ini dan semua pihak yang telah membantu hingga selesai.

\section{DAFTAR PUSTAKA}

Arma, MJ, Fermin U \& Sabaruddin, L (2013), 'Pertumbuhan dan produksi jagung (Zea mays L.) dan kacang tanah (Arachis hypogaea L.) melalui pemberian nutrisi organik dan waktu tanam dalam sistem tumpang sari', J. Agroteknos, 3 (1) Halaman 1-7.

A. Shinta (2011). Ilmu Usahatani. Malang (ID): Universitas Brawijaya Press (UB Press).

Badan Pusat Statistik, 2014. Statistik Pertanian, Badan Pusat Statistik, Jakarta, Indonesia.

Direktorat Jenderal Hortikultura. 2012. Pedoman Teknis Pelaksanaan Pengembangan Hortikultura Tahun 2012. Kementerian Pertanian, Direktorat Jenderal Hortikultura.

Ken Suratiyah. 2008. Ilmu Usahatani. Penebar Swadaya. Jakarta.

Kuncoro. (2010). Masalah, Kebijakan, dan Politik. Ekonomika Pembangunan. Erlangga, Jakarta.

Sabar Sutia dan Briman Tambunan, 2010. Analisa Break Even. Mitra Wacana Media, Jakarta.

Sugiyono. (2017). Metode Penelitian Kuantitatif, Kualitatif, dan $R \& D$. Bandung: CV Alfabeta. 